\title{
Visual information processing of sequentially presented inputs: III. Further effects of list length and interstimulus interval values on sub-span storage and retrieval mechanisms ${ }^{1}$
}

\author{
M. S. MAYZNER, ${ }^{2}$ M. E. TRESSELT, J. CHECKES, AND H. A. HOENIG \\ NEW YORK UNIVERSITY
}

Two experiments were corried out, employing a computen-based cathode-ray tube display system, to study further the effects of sub-span list length, ie, two, thee, four, and five dectimal digits, and relativeby small interstimulus interval (ISI) values, ie, 20, 40,60,80, and 100 msec, on visual information processing, storage, and retrievel mecharisins The results of the first experiment confimed the complicated interections found in two corlier studies between list length and ISI vahes, but with much smalle- ISI values than employed previousty. The results of the second experiment, in which unequal ISI vahes were employed within the same length input string, showed bittle effect resulting from this pacmeter, but it was susgested that a wider distribution of different $I S$ vahes within the same length input string would produce very strong effects.

In two previous studies (Katz, Schoenberg, \& Mayzner, 1970; Mayzner, Tresolt, Tabenkin, Didner, \& Helfer, 1969), Ss were presented with varying length strings of sequential inputs at different interstimulus interval (ISI) values. Both studies employed an "overprinting" paradigm, i.e., each input was displayed on top of the immediately preceding input. In the first study (Mayzner, Tresselt, Tabenkin, Didner, \& Helfer, 1969), the input strings were composed of two, three, or four fivefetter words, and the ISI values examined were 100, 150, 200, 250, 300, 500 , and $700 \mathrm{msec}$. In the second study (Katz, Schoenberg, \& Mayzner, 1970), the input strings were composed of two, three, four, five, six, or seven decimal digits, and slightly different ISI values were examined: $60,100,140,180,220,260$, and 300 msec. Both studies found (1) increases in per cent correct recall with increases in ISI values, at least up to an ISI value of approximately $300 \mathrm{msec}$, (2) decreases in per cent correct recall with increases in list length, and (3) complicated interactions between list length and ISI values. A general question was then posed: "Just how sensitive is the visual information processing, storage, and retrieval system to small changes in ISI values?" The present study, involving two experiments, is directed to this question.

\section{EXPERIMENT 1}

Sabjects

Ten students, selected randomly at the University Heights campus of New York University, served as Ss.

\section{Appotus}

The stimuli were presented on two Fairchild cathode-ray tube (CRT) display consoles simultaneously, both slaved to a 340 Master Display, driven by a PDP-7 digital computer. A complete description of this hardware system and its associated computer programs (software) may be found in our previous papers (Mayzner, 1968; Mayzner, Tresselt, \& Helfer, 1967a).

\section{Materials}

The stimulus materials consisted of varying length strings of single decimal digits (the digits used being 1 through 9 ). Four different string lengths were examined, i.e., two, three, four, and five digits. We did not exceed a string length of five digits, since we wanted to be especially conservative with respect to any demand introduced by "immediate memory span" limitations, and, following Miller's (1956, p. 92) estimate that seven decimal digits are within "immediate memory span" capacity, five digits certainly would seem to fulfill this demand. All digit strings were prepared by selecting and ordering the digits 1 through 9 at random, with the only constraints being that no given digit ever repeated itself in any given string and that no two strings were ever identical. Display luminance for a single digit was approximately $1 \mathrm{~mL}$ for a steady-state display, as measured with a Macbeth illuminometer. S was positioned $2 \mathrm{ft}$ in front of the display, with individual digit size fixed at $1 / 2$ in. high and $3 / 8$ in. wide. Display "on" time per digit was fixed at $10 \mathrm{msec}$, as in the two previous studies (Katz, Schoenberg, \& Mayzner, 1970; Mayzner, Tresselt, Tabenkin, Didner, \& Helfer, 1969), since extensive previous testing (Mayzner, Tresselt, \& Helfer, $1967 \mathrm{~b})$ had shown that $10 \mathrm{msec}$ provided more than ample time for $S$ to report with complete accuracy a single digit, under the conditions of individual digit size and display luminance described above.

\section{Procedure}

A 2 by 4 by 5 mixed ANOVA design was employed (Winer, 1962, pp. 324-328). Factor A (two levels) consisted of informing 5 of the 10 Ss employed, immediately prior to the presentation of each digit string, of the number of digits that would be displayed to them, while the remaining five $\mathrm{Ss}_{s}$ were given the identical information immediately after the presentation of each digit string. The actual digits were, of course, not disclosed to the Ss, just the number of digits that would be displayed, i.e., two, three, four, or five. This instructional variation was introduced since we wished to confirm our earlier finding (Katz, Schoenberg, \& Mayzner, 1970) that recall performance appears to be equally good whether Ss are told immediately prior to or immediately after the digit string is displayed to them. Thus, we hoped to find no significant difference in recall performance to result from the introduction of this instructional factor. Factor B (four levels) consisted of the length of the digit string, or list length, i.e., two, three, four, or five digits. Factor C (five levels) consisted of the different ISI values employed, i.e., $20,40,60,80$, and $100 \mathrm{msec}$. In our previous studies (Katz, Schoenberg, \& Mayzner, 1970; Mayzner, Tresselt, Tabenkin, Didner, \& Helfer, 1969), the lowest ISI value employed was $60 \mathrm{msec}$ and ISI incremental steps were either 40 or $50 \mathrm{msec}$; therefore, since the major objective of this study was to examine the sensitivity of the visual information processing, storage, and retrieval system as a function of ISI values, a very low initial ISI value, i.e., $20 \mathrm{msec}$, was selected and incremented in 20 -msec steps up to an ISI value of $100 \mathrm{msec}$. The four levels of Factor $B$ combined with the five levels of Factor $C$ yield 20 different test combinations (i.e., repeated measurements were obtained on Factors B and $C)$, and five trials per test combination were employed, yielding a grand total of 100 test trials per S. These 100 test trials were ordered randomly for each $\mathbf{S}$ tested, 


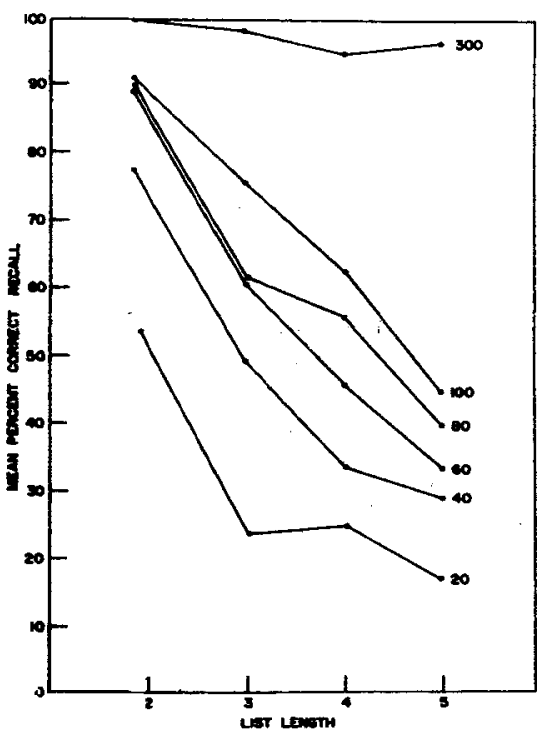

Fig. 1. Mean per cent correct recall as a function of list length for six ISI values, i.e., 20, 40, 60, 80, 100, and 300 msec. The 300 -msec ISI function is from a previous study (Katz, Schoenberg, \& Mayzner, 1970).

so that on any given trial $S$ might receive any length string at any given ISI value.

The Ss were given prepared answer forms, on which they were to write down, after each display presentation, what they could recall; they were told "ready" approximately $1 / 2 \mathrm{sec}$ before each display sequence was presented. To be scored correct, the correct digit had to recalled in its correct location in the digit string, and the Ss were so instructed. Ample time was provided between each display sequence or trial for each $\mathrm{S}$ to write down his response; this averaged about 10 to $20 \mathrm{sec}$ per trial.

\section{Results}

The major results of Experiment 1 are presented in Fig. 1 and Table 1. Since per cent correct recall scores were employed as the dependent response measure, an inverse sine transformation was applied to the raw scores prior to the ANOVA, as recommended by Edwards (1968, p. 109). The ANOVA showed clearly that Factor $A$ (i.e., told before vs told after) was very insignificant $(F=.07$, df $=1 / 8, p>.20)$, while Factors B (list length) and C (ISI values) were highly significant $(F=76.9$, df $=3 / 24, \quad p<.001$ and $F=174.2$, $\mathrm{df}=4 / 32, p<.001$, respectively); one interaction term, i.e., $B$ by $\mathbf{C}$, also was significant $(F=2.80, d f=12 / 96$, $\mathrm{p}<.005)$, confirming our previous findings (Katz, Schoenberg, \& Mayzner, 1970; Mayzner, Tresselt, Tabenkin, Didner, \&
Helfer, 1969) that list length interacts in a complicated fashion with ISI values.

Since no significant difference was found between the five Ss informed of list length immediately prior to its presentation vs the five Ss informed of list length immediately after its presentation, confirming earlier findings (Katz, Schoenberg, \& Mayzner, 1970), the results of these two different instructional groups were combined and are shown in Fig. $I$ and Table 1.

Figure 1 shows very clearly that, for ISI values ranging from 20 to $100 \mathrm{msec}$, mean per cent correct recall increases systematically as ISI values increase but decrease systematically as list length increases, confirming earlier results (Katz, Schoenberg, \& Mayzner, 1960; Mayzner, Tresselt, Tabenkin, Didner, \& Helfer, 1969), but with much smaller ISI values than were examined previously. Also, the 300-msec ISI function from our earlier study (Katz, Schoenberg, \& Mayzner, 1970) has been included to demonstrate that, when ISI values reach $300 \mathrm{msec}$, essentially $100 \%$ recall performance is obtained for all list lengths.

Table 1 presents the per cent correct recall by serial position for all list-length and ISI-value combinations, and certain trends are clearly evident. For most two-digit strings, per cent correct recall is about equal for Serial Positions 1 and 2 for most ISI values. However, for three-, four-, and five-digit strings, very marked U-shaped serial-position curves are found, confirming our earier results (Katz, Schoenberg, \& Mayzner, 1970), but with much smaller ISI values. Also, we have included, for comparison purposes, the serial-position results from our eartier study (Katz, Schoenberg, \& Mayzner, 1970) to demonstrate that, when ISI values reach $300 \mathrm{msec}$, the U-shaped serial-position curve becomes an almost straight-line function.

\section{Discusaion}

The results shown in Fig. 1 and Table 1 raise certain theoretical considerations for any visual information processing, storage, and retrieval system. First, in answer to the question posed at the beginning of this paper concerning the senuitivity of the visual system to small changes in ISI values, the results of Fig. 1 strongly suggest that ISI increments as small as 20 msec may have : profound effocts on processing, storage, and retrieval performance. In our previous studies (Katz, Schoenberg, \& Mayzner, 1970; Mayzner, Tresselt, Tabenkin, Didner, \& Helfer, 1969), employing ISI increments of 40 and 50 msec and a low ISI value of $60 \mathrm{msec}$, we found a family of functions relating per cent correct recall to list length for different ISI vahues. We had expectod that, by reducing ISI increments to only 20 moec and also employing a low ISI value of only 20 msec, we would exceed the sensitivity of the virual system to respond differentially to such small changes in ISI values. Obviously, Fig. 1 demonstrates that the visual system remains quite sensitive to such small time increments and again raises the question of just how small ISI increments can be before the system is no longer differentially responsive.

Second, the serial-position data shown in Table 1 generally confirms the serial-position analyses made in our earlier studies (Katz, Schoenberg, \& Mayzner, 1970; Mayzner, Tresselt, Tabenkin, Didner, \& Helfer, 1969). It is interesting to compare, however, the last line in Table 1 , which gives the results for an ISI value of $300 \mathrm{msec}$, with the smaller ISI values shown, which range from 20 to 100 msec. For an ISI value of $300 \mathrm{msec}$, we find essentially a straight-line function of $100 \%$ correct recall for all list lengths, while for all of the smaller ISI values examined, marked U-shaped serial-position curves are obtained, except for a list length of two. This serial-position analysis shows a rather consistent and interesting pattern of scores as ISI values are increased. Specifically, it would appear, in general, that going from a 20 -msec ISI value to a 40 -msec ISI value immediately increases recall scores for the two end positions to an asymptotic value of approximately $75 \%$ correct recall, while per cent correct recall scores for the interior serial positions rise far more gradually. Thus, this serial-position analysis

Table 1

Per Cent Correct Recell for Sexill Position Analysis $(N=10)$

\begin{tabular}{|c|c|c|c|c|c|c|c|c|c|c|c|c|c|c|}
\hline \multirow{2}{*}{$\begin{array}{c}\text { ISI } \\
\text { (msec) }\end{array}$} & \multicolumn{2}{|c|}{$\begin{array}{l}2 \text { Difit } \\
\text { String }\end{array}$} & \multicolumn{3}{|c|}{3 Digit Strin: } & \multicolumn{4}{|c|}{4 Digit String } & \multicolumn{5}{|c|}{5 Difit String } \\
\hline & 1 & 2 & 1 & 2 & 3 & 1 & 2 & 3 & 4 & 1 & 2 & 3 & 4 & 5 \\
\hline $\begin{array}{c}20 \\
40 \\
60 \\
80 \\
100 \\
300^{*}\end{array}$ & $\begin{array}{r}58 \\
72 \\
86 \\
88 \\
85 \\
100\end{array}$ & $\begin{array}{r}50 \\
84 \\
98 \\
92 \\
90 \\
100\end{array}$ & $\begin{array}{l}34 \\
66 \\
66 \\
62 \\
74 \\
98\end{array}$ & $\begin{array}{l}22 \\
14 \\
36 \\
44 \\
62 \\
98\end{array}$ & $\begin{array}{l}14 \\
68 \\
90 \\
80 \\
94 \\
98\end{array}$ & $\begin{array}{l}32 \\
72 \\
70 \\
76 \\
76 \\
96\end{array}$ & $\begin{array}{r}4 \\
8 \\
22 \\
42 \\
44 \\
92\end{array}$ & $\begin{array}{r}4 \\
16 \\
12 \\
38 \\
42 \\
92\end{array}$ & $\begin{array}{l}60 \\
58 \\
78 \\
72 \\
90 \\
96\end{array}$ & $\begin{array}{r}30 \\
60 \\
70 \\
74 \\
74 \\
100\end{array}$ & $\begin{array}{r}2 \\
2 \\
16 \\
18 \\
36 \\
98\end{array}$ & $\begin{array}{r}4 \\
2 \\
0 \\
12 \\
18 \\
94\end{array}$ & $\begin{array}{r}8 \\
10 \\
16 \\
24 \\
24 \\
92\end{array}$ & $\begin{array}{l}44 \\
72 \\
68 \\
74 \\
70 \\
90\end{array}$ \\
\hline
\end{tabular}

* The 300 msec ISI values are from a previous study (Katz, Schoenberg, \& Mayzner, 1970). 
indicates that the systematic increase in per cent correct recall shown in Fig. 1 results primarily from the increase in ISI values acting to improve retrieval performance for the interior serial positions rather than for the two end positions. This trend also obtains in our earlier studies (Katz, Schoenberg, \& Mayzner, 1970; Mayzner, Tresselt, Tabenkin, Didner, \& Helfer, 1969), although far less clearly, since ISI values were not as small and, thus, the end positions tended to show initially better performance at all ISI values examined.

\section{EXPERIMENT 2}

\section{Subjects}

The 10 students employed in Experiment 1 of the present study also served as Ss in Experiment 2.

\section{Apparatus}

The computer hardware and software configuration for Experiment 2 was identical with that employed in Experiment 1.

\section{Materials and Procedare}

The stimulus materials consisted of strings of decimal digits (the digits used being 1 through 9). Only one string length was selected for study, namely, a four-digit string, to again avoid any constraints imposed by "immediate memory span" limitations. Thirty different digit strings were prepared, forming the $\mathbf{3 0}$ trials of the experiment. The variable selected for manipulation was again ISI values. Since, with a four-digit string, three ISIs are available, three different ISI values were selected for study, namely, 20,60, and $100 \mathrm{msec}$. With each string, all three different ISI values were employed, and since, with three different ISI values, six different orderings are possible, all six orderings were examined, five trials per ordering, to yield a grand total of 30 trials; i.e., five trials had an ISI ordering of 20 , 60 , and $100 \mathrm{msec}$, another five trials had an ISI ordering of 20,100 , and $60 \mathrm{msec}$ another five trials had an ISI ordering of 60,20 , and $100 \mathrm{msec}$, etc. Thus, all 30 trials had the same number of inputs, i.e., four digits, the same total "on" time, i.e. $40 \mathrm{msec}$ (four inputs by $10 \mathrm{msec}$ "on" time per input), and the same total "off" time, or ISI values, i.e., $180 \mathrm{msec}$ $(20+60+100=180$ msec $) ;$ the only difference was in the specific ordering of ISI values within a given digit string, or trial. All other factors, such as digit size, display luminance, dependent response measure, etc., between Experiments 1 and 2 were identical.
Table 2

Per Cent Correct Recall for Serial Position Analysis for Unequal ISI Values $(\mathbf{N}=10)$

\begin{tabular}{c|rrrr|r}
\multicolumn{5}{c}{ Values $(\mathbf{N}=10)$} \\
$\begin{array}{c}\text { ISI Values } \\
\text { (msec) } \\
\text { and }\end{array}$ & \multicolumn{3}{c}{ Serial Position } & \\
\cline { 2 - 6 } Orderings & 1 & 2 & 3 & 4 & $\begin{array}{c}\text { M\% } \\
\text { Correct }\end{array}$ \\
\hline $20-60-100$ & 54 & 8 & 28 & 68 & 40 \\
$20-100-60$ & 42 & 20 & 30 & 76 & 42 \\
$60-20-100$ & 64 & 30 & 34 & 72 & 50 \\
$60-100-20$ & 64 & 34 & 18 & 54 & 44 \\
$100-20-60$ & 70 & 18 & 16 & 70 & 44 \\
$100-60-20$ & 66 & 24 & 34 & 54 & 45 \\
$60-60-60 *$ & 70 & 22 & 12 & 78 & 46 \\
\hline
\end{tabular}

-The 60-60-60 msec ordering is taken from Table 1 of Experiment 1 of the present study.

\section{Results and Discuscion}

The results of Experiment 2 are presented in Table 2. An application of the Friedman two-way analysis of variance by ranks test (Siegel, 1956, pp. 166-172) to the scores associated with the six mean per cent correct recall values, shown in the last column of Table 2, yielded a $\chi_{r}^{2}=6.2$, df $=5, p>.20$. Thus, it would appear that, over the range of specific ISI values and orderings examined, the overall output of the system remains relatively stable. Also included in Table 2 are the results obtained in Experiment 1 for an equal distribution of ISI values, i.e., the 60-60-60-msec condition, shown in the last line. Here, again, the overall mean per cent correct recall, i.e., $46 \%$, is completely in accord with the results obtained with unequal distributions of ISI values.

The per cent correct recall for each serial position also is given in Table 2 and here the results again very clearly show the marked superiority in retrieval performance for the two end positions relative to the two interior positions. There is perhaps a slight tendency for the two erid positions to yield somewhat lower scores when the input either following or preceding the end positions is separated in time from them by $20 \mathrm{msec}$; but even this difference is a small one and certainly does not obtain for the two interior positions. For example, for the 60-20-100-msec condition, per cent correct recall scores for the second and third positions, which are separated by only $20 \mathrm{msec}$, are $30 \%$ and 34\%, respectively, while with the 20-100-60-msec condition, per cent correct recall scores for the second and third positions, which are now separated by $100 \mathrm{msec}$ and therefore should show improved retrieval performance, are only $20 \%$ and $30 \%$, respectively.

While the results shown in Table 2 certainly appear to indicate that was not great enough for the system to respond to differentially. Certainly, had we selected, for example, an ISI time distribution such as 1-178-1 msec, we feel confident that marked differences in system output would have occurred, in contrast to a $60-60-60-\mathrm{msec}$ ISI time distribution. Again, a basic question for visual information-processing models is raised: "How unequal must ISI times be made before system output begins to vary?"

\section{REFERENCES}

EDWARDS, A. L. Experimental design in psychological research. (3rd ed.) New York: Holt, Rinehart, \& Winston, 1968.

KATZ, M., SCHOENBERG, K. M., \& MAYZNER, M. S. Visual information processing of sequentially presented inputs: II. Effects of list length and interstimulus interval values on sub-span storage and retrieval mechanisms. Perception \& Psychophysics, 1970, 0, 000-000.

MAYZNER, M. S. The research potential of a computer-based cathode-ray tube display system. Behavior Research Methods \& Instrumentation, 1968, 1, 41-43.

MAYZNER, M. S., TRESSELT, M. E., \& HELFER, M. S. A research strategy for studying certain effects of very fast sequential input rates on the visual system. Psychonomic Monograph Supplements, 1967a, 2(5, Whole No. 21), 73-81.

MAYZNER, M. S., TRESSELT, M. E., \& HELFER, M. S. A provisional model of visual information processing with sequential inputs. Psychonomic Monograph Supplements, 1967b, 2(7, Whole No. 23), 91-108.

MAYZNER, M. S., TRESSELT, M. E., TABENKIN, N., DIDNER, R., \& HELFER, $M$. S. Visual information processing of sequentially presented inputs: I. Effects of input timing on sub-span storage and retrieval mechanisms. Perception \& Psychophysics, 1969, 5, 297-302.

MILLER, G. A. The magical number seven, plus or minus two: Some limits on our capacity for processing information. Psychological Review, 1956, 63, 81-97.

SIEGEL, S. Nonparametric statistics for the behavioral sciences. New York: McGraw-Hill, 1956.

WINER, B. J. Statistical principles in experimental design. New York: McGraw-Hill, 1962.

\section{NOTES}

1. This research was supported by Grant No. GB-8037 from the National Science Foundation to the first author.

2. Address: 15 Sydney Avenue, Deal, New Jersey 07723 .

(Accepted for publication August 15, 1969.) 